\title{
ADIÇÃO DE FERRO AO LEITE E SUA RETENÇÃO NA COALHADA DESSORADA ${ }^{1}$
}

\author{
Tiane Franco Barros MANGUEIRA ${ }^{2, *}$, Antonio Eustaquio Resende TRAVASSOS ${ }^{2,3}$, \\ Romeu FIOREZE², Rosália Severo de MEDEIROS ${ }^{2}$
}

\section{RESUMO}

Além do ferro ser muito pouco absorvido pelo organismo poucos alimentos contêm ferro em quantidade considerável. Assim, faz-se necessário estudar meios de enriquecimento estratégico de alguns alimentos. O aumento do teor de ferro no leite mediante um processo de coagulação poderia ser de utilidade visando obter um produto nutricionalmente mais completo. $\mathrm{O}_{\text {ferro, }}$ na forma de $\mathrm{Fe}\left(\mathrm{NH}_{4}\right)_{2}\left(\mathrm{SO}_{4}\right)_{2} \cdot 6 \mathrm{H}_{2} \mathrm{O}$, foi adicionado ao leite de vaca em dosagens de 15, 20 e $25 \mathrm{mg}$ de $\mathrm{Fe} / 100 \mathrm{ml}$ e sua concentração determinada na coalhada dessorada e no soro. Foi observado que a maior parte de ferro adicionado ao leite fica retida na coalhada dessorada em um proporção superior a $70 \%$ para as três dosagens estudadas e que conforme a quantidade de ferro adicionado aumenta, a taxa de retenção também aumenta, exceto para a dosagem mais elevada.

Palavras-chave: leite; coalhada dessorada; retenção de ferro.

\section{SUMMARY}

ADDITION OF IRON TO THE MILK AND ITS RETENTION IN THE CURD. Besides Iron having a limited absorption by the body, few foods contain iron in considerable amounts. Therefore, it is useful to consider the strategic enrichment of certain foods. Adding iron by means of a clotting process may prove to be a plausible procedure to increase the content of iron in cow's milk. Iron in the form of $\mathrm{Fe}\left(\mathrm{NH}_{4}\right)_{2}\left(\mathrm{SO}_{4}\right)_{2} \cdot 6 \mathrm{H}_{2} \mathrm{O}$ (concentrations of 15,20 and $25 \mathrm{mg}$ of $\mathrm{Fe} / 100 \mathrm{~mL}$ ) was added to cow's milk and the contents determined in both the curd and in the whey. It was observed that for the most part iron added to the milk was retained in the curd in a per-cent greater than $70 \%$ for the three levels tested and that as the amount of iron added increased, the per-cent retention also increased, with the exception of the highest concentration.

Keywords: milk; curd; retention of iron.

\section{1 - INTRODUÇÃO}

A falta de ferro é a mais importante deficiência nutricional do mundo, e se a anemia é usada como um indicador de insuficiência de ferro, estima-se que 30\% a $60 \%$ das mulheres e crianças de países em desenvolvimento sejam carentes desse mineral (Organização Mundial da Saúde, citado por NOGUEIRA et. al., [8]). O que também é afirmado por FRANCO [4], para quem a deficiência de ferro é a causa mais comum da anemia nutricional no homem.

O ferro do organismo tem dupla origem: ferro exógeno, ingerido com os alimentos e ferro endógeno, proveniente da destruição das hemácias, que libera cerca de $27 \mathrm{mg}$ do metal, sendo em seguida reutilizado. O ferro dos alimentos não é inteiramente aproveitado pelo organismo, dependendo da forma sob a qual é ingerido, isto é, de sua separação das combinações químicas sob as quais se apresenta, pois para sua absorção é necessário que seja solúvel, ionizável e ultrafiltrável [4].

De acordo com LOTUFO [5], na alimentação normal, as principais fontes de ferro são a carne e o feijão. Mas seria necessário comer muito desses dois alimen-

1. Recebido para publicação em 18/02/2000. Aceito para publicação em 23/03/2002.

2. Universidade Federal da Paraíba, Depto. de Tecnologia Quimica e de Alimentos, Centro de Tecnologia, Campus I, João Pessoa/PB. CEP 58051970.E-mail:cpgcta@ct.ufpb.br.

3. Universidade Federal da Paraiba, Depto. de Tecnologia Rural, Centro de Formação de Tecnólogos, Campus IV, Bananeiras/PB. CEP 58000000.E-mail: aertjp@yahoo.com.br.

* A quem a correspondência deve ser enviada. tos para se alcançar a Ingestão Diária Recomendada IRD, padrão internacional recomendado por especialistas, do mineral. A dose diária de ferro recomendada para adultos, em estado físico normal é de 10 a $15 \mathrm{mg}$ do elemento por $100 \mathrm{~g}$ ou $100 \mathrm{~mL}$ do alimento [1].

Com o objetivo de ajudar a prevenir a anemia em crianças de até cinco anos, foi testado por Fisberg pediatra da Universidade Federal de São Paulo, citado por LOTUFO [5], a utilização do queijo tipo petit suisse enriquecido com ferro, onde obteve-se resultados satisfatórios, os quais ajudaram a melhorar as reservas deste mineral no organismo das crianças.

Poucos alimentos contêm ferro em quantidade considerável [2], mesmo assim ele é muito pouco absorvido pelo organismo. Assim, faz-se necessário o enriquecimento de algum alimento para possibilitar que quantidades suficientes sejam consumidas.

O presente trabalho tem como objetivo verificar os niveis de ferro que ficaram retidos na coalhada, após a retirada do soro, obtido com leite enriquecido com diferentes dosagens deste elemento.

\section{2 - MATERIAL E MÉTODOS}

O ensaio foi conduzido no Laboratório de Bioquímica de Alimentos do Centro de Tecnologia e no Laboratório de Instrumentação e Automação em Química Analítica do Centro de Ciências Exatas e da Natureza, pertencentes à Universidade Federal da Paraíba - Campus I, João Pessoa - PB.

A matéria-prima utilizada para elaboração da coalhada dessorada foi o leite in natura. 
A obtenção da coalhada dessorada enriquecida com ferro está apresentada no fluxograma da Figura 1, contendo as descrições das principais etapas.

Leite: O leite utilizado foi proveniente de vacas sadias, com cor e odor característicos, resultante de ordenha manual, coletado em garrafas plásticas, imediatamente após a ordenha.

Filtração: O leite foi filtrado com auxilio de tela de malha fina. Após filtrado foi dividido em 4 recipientes de aluminio, contendo 1 litro de leite cada.

Adição de Ingredientes: Foi adicionado em três dos recipientes (ficando um sem adição, apenas com o coalho) o ferro na forma de sulfato ferroso amoniacal $\left(\mathrm{Fe}\left(\mathrm{NH}_{4}\right)_{2}\left(\mathrm{SO}_{4}\right)_{2} \cdot 6 \mathrm{H}_{2} \mathrm{O}\right)$, em proporções diferentes: 15, 20 e $25 \mathrm{mg}$ do mineral por $100 \mathrm{~mL}$ de leite. Em seguida adicionou-se o coalho liquido, de origem animal, de acordo com a orientação do fabricante, em quantidades iguais para todos os recipientes. Após a adição dos ingredientes, fez-se uma homogeneização manual.

Coagulação: A coagulação empregada foi a enzimática. O leite permaneceu em repouso durante 40 a 60 minutos, em temperatura ambiente.

Corte da Coalhada: Foi feita com o auxilio de uma faca em aço inoxidável no sentido vertical e horizontal. Em seguida, a coalhada foi levemente agitada.

Repouso: Após a realização do corte da coalhada, o leite ficou em repouso até que todos os grãos de massa ficassem separados do soro.

Dessoramento: Após a separação dos grãos da massa, o soro foi retirado cuidadosamente, e para aumentar a eficácia do dessoramento, a massa obtida foi colocada em tela de malha fina e prensada.

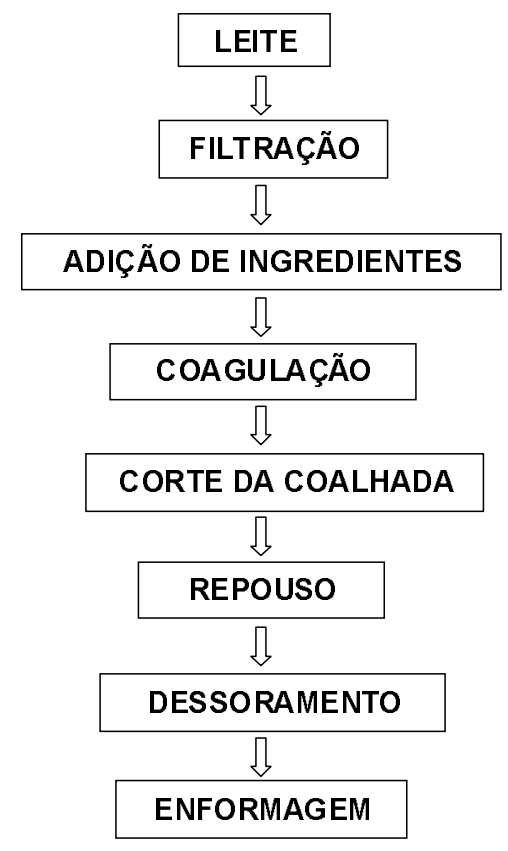

FIGURA 1. Fluxograma de obtenção da coalhada dessorada enriquecida com ferro.
Enformagem: A massa foi retirada da tela e colocada em formas de plástico. O soro foi transferido para recipientes de vidro de onde foram retiradas as amostras para análise química. O restante do material foi colocado sob refrigeração para futuras análises se necessário.

\section{1 - Determinação de Ferro}

A determinação do teor de ferro na coalhada dessorada e no soro, foi realizada segundo a metodologia descrita por RANGANA [9]. Foi utilizado o espectrofotômetro digital B 34211 da Micronal. A quantidade de ferro complexado na coalhada dessorada, foi determinada pela diferença entre esta, e a quantidade de ferro existente no leite (branco).

\section{3 - RESULTADOS E DISCUSSÃO}

Os resultados obtidos na determinação de diferentes dosagens de ferro, adicionadas no leite e avaliadas na coalhada dessorada, encontram-se na Tabela 1 , juntamente com as quantidades desse mineral encontradas no soro, onde R1, R2 e R3 correspondem as repetições de uma mesma amostra.

TABELA 1. Niveis de ferro totais na coalhada dessorada e no soro, com suas respectivas médias, após adição de ferro ao leite.

\begin{tabular}{|c|c|c|c|c|c|c|c|c|}
\hline \multirow{2}{*}{$\begin{array}{l}\text { Dosagens de Ferro } \\
\text { adicionadas ao leite }\end{array}$} & \multicolumn{4}{|c|}{$\begin{array}{c}\text { Coalhada dessorada } \\
(\mathrm{mg} / 100 \mathrm{~g})\end{array}$} & \multicolumn{4}{|c|}{$\begin{array}{c}\text { Soro } \\
(\mathrm{mg} / 100 \mathrm{~mL})\end{array}$} \\
\hline & $\mathrm{R} 1$ & $\mathrm{R} 2$ & R3 & Média & $\mathrm{R} 1$ & $\mathrm{R} 2$ & $\mathrm{R} 3$ & Média \\
\hline Branco & 4,63 & 5,33 & 7,64 & 5,87 & 1,50 & 2,29 & 1,10 & 1,63 \\
\hline $15 \mathrm{mg} \mathrm{Fe} / 100 \mathrm{~mL}$ & 18,72 & 19,26 & 20,00 & 19,33 & 1,60 & 1,40 & 2,10 & 1,70 \\
\hline $20 \mathrm{mg} \mathrm{Fe} / 100 \mathrm{~mL}$ & 22,95 & 21,60 & 24,30 & 22,95 & 3,29 & 2,99 & 2,28 & 2,63 \\
\hline $25 \mathrm{mg} \mathrm{Fe} / 100 \mathrm{~mL}$ & 25,29 & 26,61 & 23,62 & 25,17 & 2,40 & 2,28 & 2,48 & 2,39 \\
\hline
\end{tabular}

Os niveis de ferro encontrados no soro, no presente trabalho, serviram de base apenas para efeito comparativo em relação àqueles observados na coalhada dessorada, pois, parte do ferro adicionado ao leite após a coagulação, deve ficar retida no soro, sendo este descartado durante o processo de fabricação do queijo de coalho.

Nas quantidades totais de ferro obtidos na coalhada dessorada, estão contidas as já existentes no branco (leite sem adição de ferro) e isso ocorre, provavelmente, devido à presença da lactoferrina, que é uma proteina presente no leite, que contém ferro em pequena quantidade, atuando assim de forma benéfica no produto, diminuindo o desenvolvimento dos microrganismos no leite [10].

Os dados médios referentes aos niveis de ferro retidos na coalhada dessorada e no soro, já descontado o valor médio do ferro encontrado no leite, estão apresentados na Tabela 2. A retenção de ferro observada na coalhada dessorada foi proporcional ao aumento das dosagens de ferro, que foram adicionadas no leite antes da coagulação. 
Para os três niveis de ferro adicionados ao leite, foram observadas retenções de ferro superiores a $70 \%$, sendo a menor retenção $(77,20 \%)$ encontrada na dosagem de $25 \mathrm{mg}$ de $\mathrm{Fe} / 100 \mathrm{~mL}$ de leite, e a maior $(87,47 \%)$ na dosagem de $15 \mathrm{mg}$ de $\mathrm{Fe} / 100 \mathrm{~mL}$ de leite. Para haver essa retenção de ferro na coalhada dessorada, provavelmente, o mineral se agrega aos aminoácidos que formam a proteina [3], em particular com a caseína que é a proteína principal responsável pela obtenção da coalhada.

TABELA 2. Médias com desconto do branco, das repetições dos niveis de ferro na coalhada dessorada e no soro, após adição de ferro ao leite.

\begin{tabular}{ccccc}
\hline Dosagens de Ferro & \multicolumn{2}{c}{ Coalhada dessorada } & \multicolumn{2}{c}{ Soro } \\
\cline { 2 - 5 } adicionadas ao leite & $\mathrm{mg} / 100 \mathrm{~g}$ & $\%$ & $\mathrm{mg} / 100 \mathrm{~mL}$ & $\%$ \\
\hline $15 \mathrm{mg} \mathrm{Fe} / 100 \mathrm{~mL}$ & 13,12 & $87,47 \%$ & 0,07 & $0,47 \%$ \\
$20 \mathrm{mg} \mathrm{Fe} / 100 \mathrm{~mL}$ & 17,08 & $85,00 \%$ & 1,00 & $5,00 \%$ \\
$25 \mathrm{mg} \mathrm{Fe} / 100 \mathrm{~mL}$ & 19,30 & $77,20 \%$ & 0,76 & $3,04 \%$ \\
\hline
\end{tabular}

Como foi observado, encontrou-se um menor percentual de ferro na maior dosagem adicionada, podendo ser levado em consideração a possibilidade de saturação da capacidade de retenção de ferro adicionada [7], pois esses quelatos formados pelos aminoácidos em presença desse mineral [3] podem ser limitados.

A deficiência de ferro é uma desordem nutricional, com alta prevalência, não só nos países em desenvolvimento, como também nos paises desenvolvidos [6].

Como o consumo diário de queijo na população de um modo geral não é tão grande e há necessidade de $10 \mathrm{mg}$ a $15 \mathrm{mg}$ de ferro por dia [1], o ideal seria ingerir o mesmo com alta concentração de ferro. Neste caso, a dosagem de $25 \mathrm{mg}$ de $\mathrm{Fe} / 100 \mathrm{~mL}$ de leite, com retenção de 19,30mg de $\mathrm{Fe} / 100 \mathrm{mg}$ na coalhada dessorada, pode fornecer um queijo rico nesse mineral.

Com os resultados obtidos no presente trabalho, pode-se afirmar que a quantidade de ferro adicionada ao leite, ficou retida em sua maioria na coalhada dessorada, obtendo valores relativamente pequenos no soro.

\section{4 - CONCLUSÕES}

- A grande parte de ferro adicionado fica retida pela coalhada dessorada. No soro, praticamente não há alteração.

- Em todas as amostras, mais de 70\% da quantidade de ferro adicionado, ficou retida na coalhada dessorada.
- Conforme a quantidade de ferro adicionado aumenta, a retenção também aumenta, porém, nas adições de 20 e $25 \mathrm{mg}$ de $\mathrm{Fe} / 100 \mathrm{~mL}$ de leite, a quantidade percentual (85,00\% e 77,20\%, respectivamente) do mineral retido foi menor, comparando-se com o percentual $(87,47 \%)$ da adição de $15 \mathrm{mg}$ de Fe/100mL de leite.

\section{5 - REFERÊNCIAS BIBLIOGRÁFICAS}

[1] ASSOCIAÇÃO BRASILEIRA DAS INDÚSTRIAS DA ALIMENTAÇÃO - ABIA. Compêndio da Legislação de Alimentação: Alimentos Enriquecidos - Resolução da Comissão Nacional de Normas e Padrões para Alimentos (CNNPA) M/S 12/78. Sub-item 12/46. São Paulo, 1978. Reunião 3. (7.32 (78)).

[2] ATHERTON, H.V.; NEWLANDER, J.A. Chemistry and testing of dairy products. 4 ed. United States: Avi, 1982, 396p. il.

[3] BOBBIO, F.O.; BOBBIO, P.A. Introdução à química de alimentos. 2 ed. São Paulo: Varela, 1995. 223p. il.

[4] FRANCO, G. Tabela de composição química dos alimentos. 9 ed. Rio de Janeiro: Atheneu, 1995. 307p.

[5] LOTUFO, T. Solução na mesa: Novas categorias de alimentos revolucionam o cardápio e a saúde do brasileiro. ISTO É. São Paulo, no 1555, p. 136-137, Jul. 1999.

[6] MACPHAIL A.P.; BOTHWELL T.H. The prevalences and causes of nutritional iron deficiency anemia. In: Nutritional anemias. Eds. Fomon, S. J. \& Ztotkin, S. Nestle Nutrition Work-Shop Series, 30:1-12, Raven Press, Ney York, 1992.

[7] MAHAN, L.K.; ESCOTT-STUMP, S. Krause: Alimentos, nutrição e dietoterapia. 9 ed. São Paulo: Roca, 1998. 1179p. il.

[8] NOGUEIRA, N. N., MARREIRO, D. N., PARENTE, J. V., COZZOLINO, S. M. F. P. Estado nutricional de adolescentes grávidas suplementadas com ferro, zinco e ácido fólico. In: CONGRESSO BRASILEIRO DE CIÊNCIA E TECNOLOGIA DE ALIMENTOS, 1, 1998, Rio de Janeiro. Anais... Rio de Janeiro, 1998.

[9] RANGANA, S. Manual of analisis of fruit and vagetable products. New Delhi: Tata Mc Graw-Hill, 1979.

[10] TRONCO, V.M. Manual para inspeção da qualidade do leite. Santa Maria. UFSM, 1997. 166p. il.

\section{6 - AGRADECIMENTOS}

Ao Laboratório de Bioquímica de Alimentos do Centro de Tecnologia (CT) e ao Laboratório de Instrumentação e Automação em Química Analítica do Departamento de Química do Centro de Ciências Exatas e da Natureza (CCEN), pertencentes à Universidade Federal da Paraíba - Campus I, João Pessoa/PB, pelo apoio concedido na realização das análises. 